\title{
Skin Sparing Mastectomy and Immediate Breast Reconstruction (SSMIR) for early breast cancer: Eight years single institution experience Ramesh Omranipour*1,2, Jean yves Bobin ${ }^{1}$ and Mustafa Esouyeh ${ }^{1}$
}

\author{
Address: ${ }^{1}$ Current-Department of Surgical Oncology, Cancer Institute, Tehran University Of Medical Science, Tehran, Iran and ${ }^{2}$ Department of \\ Surgical Oncology, Lyon Sud Hospital, 69495 Pierre Benite cedex, France \\ Email: Ramesh Omranipour* - omranipour@sina.tums.ac.ir; Jean yves Bobin - omranipour@sina.tums.ac.ir; \\ Mustafa Esouyeh - mustafaesuyeh@yahoo.com \\ * Corresponding author
}

Published: 27 April 2008

World Journal of Surgical Oncology 2008, 6:43 doi:10.1 186/1477-7819-6-43

This article is available from: http://www.wjso.com/content/6/1/43

(c) 2008 Omranipour et al; licensee BioMed Central Ltd.

This is an Open Access article distributed under the terms of the Creative Commons Attribution License (http://creativecommons.org/licenses/by/2.0), which permits unrestricted use, distribution, and reproduction in any medium, provided the original work is properly cited.
Received: 12 August 2007

Accepted: 27 April 2008

\begin{abstract}
Background: Skin Sparing Mastectomy (SSM) and immediate breast reconstruction has become increasingly popular as an effective treatment for patients with breast carcinoma. The aim of this study was to evaluate the clinical outcome of skin sparing mastectomy in early breast cancer at a single population-based institution.
\end{abstract}

Methods: Records of ninety-five consecutive patients with operable breast cancer who had skinsparing mastectomy and immediate breast reconstructions between 1995 and 2003 were reviewed. Patient and tumor characteristic, type of reconstruction, postoperative complications, aesthetic results and incidence of recurrence were analyzed.

Results: Mean age of the patients was 5I.6(range 33-72) years. The AJCC pathologic stages were $0(n=5 I, 53.7 \%), I(n=20,2 I . I \%)$, and II $(n=2,2.1 \%)$. Twenty of the patients had recurrent disease (2I.I\%). The immediate breast reconstructions were performed with autologus tissue including latissimus dorsi musculocutaneous flap in 63 (66.3\%) patients and transverse rectus abdominis myocutaneous (TRAM) flap in 4 (4.2\%) patients. Implants were used in $28(29.4 \%)$ patients. The average hospital stay was 7.7 days. Flap complication occurred in seven $(10.4 \%)$ patients resulting in four $(6 \%)$ re-operations and there were no delay in accomplishing postoperative adjuvant therapy. At a median follow-up of 69 months (range 48 to 144), local recurrence was seen in one patient (I.I\%) and systemic recurrence was seen in two patients $(2.1 \%)$.

Conclusion: Skin sparing mastectomy and immediate breast reconstruction for early breast cancer is associated with low morbidity and low rate of local recurrence.

\section{Background}

Skin sparing mastectomy (SSM) has become a popular method for surgical treatment of early stage breast cancer. This technique was described by Toth and Lappert in 1991 [1]. It consists of a standard mastectomy with resection of nipple-areola complex and biopsy scar that preserves the native skin envelope as much as possible. Preservation of inframammary fold and breast contour facilitates immediate breast reconstruction and provides an ideal color and texture match of the reconstructed breast and the 
opposite breast. The small scar of SSM could be concealed in periareolar location, this and the low probability of nipple-areola complex involvement in early breast cancer [2-5], has made skin sparing mastectomy with nipple- areola complex preservation as an ideal method regarding oncological safety and cosmetic results in selected cases [6].

The risk of skin involvement in $\mathrm{T} 1$ and $\mathrm{T} 2$ breast carcinoma is very small [7] and the local recurrence after skin sparing mastectomy is a reflection of tumor biology rather than the amount of skin preserved [8-10].

A United King study in 2004 found that 95, 85 and 63 percent of breast surgeons would consider using SSM for DCIS, T1 and T2 tumors respectively, and 17 percent would consider the procedure for the treatment of T3 tumors [11]. Many studies have evaluated the local recurrence rate and survival rate of SSM and immediate reconstruction in early breast cancer [12-15]. The incidence of local recurrence after SSM has been reported as $0-7 \%$ $[16,17]$.

The purpose of this study has been to evaluate postoperative morbidity, aesthetic result and safety of SSM in the management of early breast cancer in our department.

\section{Patients and methods}

Ninety-five consecutive patients were reviewed in this study that were operated on by the skin-spare mastectomy procedure for their early breast cancer (stage 0, 1, and 2) and followed by immediate breast reconstruction surgery at surgical oncology department, Lyon Sud hospital from April 1995 to April 2003. Chart review was done by one surgeon (J.Y.B). Only the patients were included in this study that were followed for at least four years. Follow-up records gathered from patient's surgical files completed by their surgeon AJCC staging system [18] was utilized to classify breast cancers. Indications for operation were categorized as; primary breast cancer including those with multicentric tumors or the ones with positive surgical margins after second lumpectomy ( $\mathrm{n}=73,76.8 \%)$; recurrence following breast conservation surgery and adjuvant radiotherapy $(n=20,21.1 \%)$; deformity and microcalcification after breast conservation surgery $(n=1$,$) , and pro-$ phylactic mastectomy $(n=1)$. All the patients were discussed regarding different options for their breast reconstruction surgery before admission.

Skin sparing mastectomy has been classified according to the type of surgical incision, the amount of skin to be removed, and the pattern of skin removal. The choice of incision was chosen according to the size of breast, the location of the previous biopsy scar, location of the tumor and to the surgeon preference. Tennis Racquet and periar- eolar incisions comprised the most common type of the incisions in our series.

There was Periareolar incisions when a core needle biopsy was done or a prophylactic mastectomy was planned. A sentinel node biopsy or an axillary dissection was performed as indicated. Obviously, patients with positive sentinel node underwent axillary lymph node dissection.

Immediate breast reconstruction techniques were either autologus tissue transfer muscle flaps (Latissimus dorsi or Rectus abdominis) or implants. Nipple- areola complex reconstruction were planned to be done three months afterward as a separate procedure. A mamoreduction procedure for the opposite breast was performed in the first reconstruction operation session.

Adjuvant chemotherapy and radiotherapy were scheduled when indicated according to the tumor characteristics and stage of the disease. There were no delay in adjuvant therapies in case of any given breast reconstruction complications.

Follow up protocols included a 3- or 6-month clinical review and annual mammography. Patients' median follow up was 69 months (48 to 144). Patients were followed until April 2007 in this study. All data were entered into a dedicated data base (Microsoft Access 2000) and were analyzed using SPSS 11.5 for windows.

\section{Results}

The mean age of patients was 51.6(range 33-72) and most of them ( $n=82,86.3 \%)$ were perimenopause and postmenopause women who were referred because of abnormality in screening mammography (microcalcification in $76(80 \%)$ patients, nodule in $2(2 \%)$ patients, other abnormalities in 4 (4\%) patients). Only $13(13.7 \%)$ patients were symptomatic (seven (7.4\%) patients with mass, six (6.3\%) patients with discharge and pain).

Positive family history was recorded in 24 (25.3\%) patients (first degree in $18(18.9 \%)$ and second degree in six $(6.3 \%)$ patients). The diagnosis of breast cancer was histologically proven by core cut or needle biopsy in 34 (35.8\%) patients or by open biopsy in $61(64.2 \%)$ patients.

The American Joint Cancer Congress staging were $0(\mathrm{n}=$ $51,53.7 \%)$, I $(\mathrm{n}=20,21.1 \%)$, II $(\mathrm{n}=2,2.1 \%)$, recurrent $(\mathrm{n}=20,21.1 \%)($ table 1$)$. There was one case of atypical lobular hyperplasia with the history of invasive lobular cancer in opposite breast and one case of deformation and microcalcification after breast conservative therapy. 
Table I: Tumor Characteristics

\begin{tabular}{rl}
\hline Variable & No of patients (\%) \\
\hline $\begin{array}{c}\text { Tumor classification } \\
\text { Non invasive } \\
\text { Comedo } \\
\text { non-comedo } \\
\text { Invasive }\end{array}$ & $58(61 \%)$ \\
Tumor location $\quad$ Central & $22(23.1 \%)$ \\
Upper pole & $35(36.8 \%)$ \\
Lower pole & $13(13.6 \%)$ \\
Multicentric & $37(38.9 \%)$ \\
AJCC Staging $\quad 22(23.1 \%)$ \\
I & $22(23.1 \%)$ \\
2 & $51(53.6 \%)$ \\
Recurrent & $20(21 \%)$ \\
Grading of the invasive tumors & $2(2.1 \%)$ \\
I & $20(21 \%)$ \\
II & $8(8.4 \%)$ \\
III & $20(21 \%)$ \\
\end{tabular}

In the first half of study (1995-1999), most of the operations were performed by tennis racquet incision and in the second half (1999-2003) most of them were performed by periareolar incision. This shift may be due to more early diagnosis of breast cancer and more use of stereotactic technique in diagnosis of breast carcinoma. All the margins of mastectomy were negative and the rate of malignant involvement of nipple-areole complex was $6.3 \%$. Management of axilla includes: sentinel node biopsy $(\mathrm{n}=13,13.6 \%)$, axillary dissection $(\mathrm{n}=24$, $25.2 \%)$ with $11(11.5 \%)$ sampling, $13(13.6 \%)$ conventional dissection, and with no intervention $(\mathrm{n}=45$, $47.3 \%$ ). Thirteen patients had history of previous axillary dissection at the time of breast conservative surgery. Sen- tinel nodes were positive only in two patients who underwent subsequent axillary dissection.

For immediate breast reconstruction, we preferred the Latissimus dorsi flap ( $\mathrm{n}=63,67 \%)$ completely mobilized by dividing of humeral head. A permanent implant was inserted under flap in $28(29 \%)$ patients to achieve optimal volume. TRAM flap was used only in $4(4 \%)$ patients who were obese and required a voluminous flap. Implant reconstruction was used only when the patient $(\mathrm{n}=28$, $29 \%$ ) did not accept any additional incision on the skin.

Surgical complications are recorded in table 2 separately according to the type of reconstruction. The most common complication in latissimus dorsi group was seroma formation in donor site $(\mathrm{n}=20,31.8 \%)$ which was managed most often conservatively, open drainage was needed in $3(15 \%)$ patients.

Skin loss in breast envelope flap requiring debridement and local wound care occurred in $6(6.3 \%)$ patients, four $(66.6 \%)$ underwent resection and primary closure (including three implant removals) and two (33.3\%) healed by secondary closure. Three of them (50\%) had history of breast radiation and nobody was smoker.

Hospital stay was 7.7 days (range 3-19). Eighteen Patients $(18.9 \%)$ received adjuvant systemic chemotherapy. Adjuvant Tamoxifen was given to $31(32.6 \%)$ patients. Postoperative radiotherapy was given to $3(3.2 \%)$ patients.

Contra-lateral surgeries including reduction mammoplasty and mastopexy were done in $18(18.9 \%)$ patients at the same time of nipple-areole reconstruction. Minority of patients in this study $(\mathrm{n}=11,11.5 \%)$ have needed implant exchange either because of deformation, dis-

Table 2: Complications of Skin Sparing Mastectomy and immediate reconstruction according to the type of reconstruction

\begin{tabular}{|c|c|c|c|}
\hline Complication & LD $\pm P$ & TRAM & Prosthesis \\
\hline \multicolumn{4}{|l|}{ Flap related } \\
\hline Partial skin envelope necrosis & $3(4.8 \%)$ & 0 & $3(10.8 \%)$ \\
\hline Partial Flap necrosis & I (I.6\%) & 0 & 0 \\
\hline Periareolar dehiscence & $2(3.2 \%)$ & 0 & 0 \\
\hline Contracture and need denervation & $\mathrm{I}(\mathrm{I} .6 \%)$ & 0 & 0 \\
\hline \multicolumn{4}{|l|}{ Donor site related } \\
\hline Seroma & $20(31.8 \%)$ & I (25\%) & $2(7.1 \%)$ \\
\hline Haematoma & $4(6.3 \%)$ & 0 & 0 \\
\hline Superinfection of seroma/haematoma & $6(9.5 \%)$ & 0 & 0 \\
\hline Back pain & $8(12.7 \%)$ & 0 & 0 \\
\hline Hernia & 0 & $\mathrm{I}(25 \%)$ & 0 \\
\hline \multicolumn{4}{|l|}{ Implant related } \\
\hline Displacement & 0 & 0 & $7(25 \%)$ \\
\hline Capsular formation & 0 & 0 & $2(7.1 \%)$ \\
\hline Total & $45(71.4 \%)$ & $2(50 \%)$ & | 4(50\%) \\
\hline
\end{tabular}


placement or achieving a more symmetry. Contra-lateral surgery was needed in $18(18.9 \%)$ patients, confirming better symmetry and decreasing the rate of contra-lateral surgery after skin sparing mastectomy in comparison with non-skin sparing mastectomy.

The final aesthetic results were recorded by another surgeon (M.E) visiting the patients in clinic at least 6 month after operation. There were classified as excellent $(\mathrm{n}=34$, $35.8 \%)$, good $(\mathrm{n}=54,56.8 \%)$, and fair $(\mathrm{n}=7,7.3 \%)$ according to the Lowery Scaling System [19].

There was one case of regional recurrence in axilla 41 months after skin sparing mastectomy for an in situ carcinoma. There was no invasive component in the mastectomy specimen of this patient. With more evaluation of this case distant metastasis were found in the bone and liver and the patient died in 10 months despite systemic therapy. There was another case of distant metastasis in liver 26 months after treatment of an invasive node positive carcinoma; the patient died in 8 months after diagnosis of distant metastasis.

There was one case of second primary invasive cancer of the opposite breast after two years elapsed of the primary cancer, which was treated by the same SSM technique. One smoker patient developed metachronous metastatic lung cancer five years after treatment for her breast carcinoma. The patient died during last follow up. Three patients died because of cardiac events.

\section{Discussion}

Rising popularity of skin sparing mastectomy is due to better understanding of tumor biology and pattern of recurrence. Data showed that most of patients with local recurrence would progress to distant metastasis and the local recurrence could not be considered as an isolated event resulting from inadequate resections. As with all other types of mastectomy, SSM leaves some residual breast tissue behind but it has been proved that the stage of the primary tumor is the dominant predictor of local recurrence rather than the amount of tissue remains under skin flap.

In SSM the endangered breast tissue could be removed with safe margins while the spared skin could still function cosmetically. The ideal SSM would have flap thin enough to remove all breast tissue, but thick enough to support an adequate blood supply. Torresan et al. [20], showed a high prevalence of glandular breast tissue and residual disease in the skin flap thicker than $5 \mathrm{~mm}$. As with standard mastectomy, obtaining free surgical margins is essential to skin sparing mastectomy.
The inframammary fold could be left undisturbed and the thickness of the flap could be the same as those in modified radical mastectomy. Carlson et al. [21] examined the inframammary fold tissue in patients undergoing skinsparing mastectomy. They found breast tissue in 13 out of 24 specimens, but these tissues comprised only $0.02 \%$ of the total area. Slavin et al. [12] examined 114 skin biopsies from 32 patients undergoing skin-sparing mastectomy, and they found none of the biopsies containing remnant of breast ductal tissue in the dermis. Using SSM, the reconstructive surgery has changed from a prolonged procedure to a more rapid operation in which the reconstructive tissue fills the native skin envelope.

While skin flap necrosis is a recognized complication of SSM because the skin envelope's blood supply can become compromised during dissection, this could be avoided by selecting patients appropriate for the procedure. Nicotine, previous radiotherapy, diabetes and obesity increase the risk of skin envelope ischemia, skin necrosis and infection. These factors could amplify these complications additively, so they should be fully explained to patients before obtaining consent for the operation [22]. Skin flap necrosis has been estimated to occur in $11 \%$ of SSM as well as non-SSM cases [13]. In this study we observed very low level of morbidity associated with this procedure. There were six patients (6.3\%) with skin envelope ischemia in our series, and three of them $(50 \%)$ with the history of breast irradiation.

Adjuvant treatment does not seem to be commonly delayed for a possible skin necrosis following SSM and immediate breast reconstruction [23,24], although extensive skin envelope necrosis could delay adjuvant treatment in a few individuals affected.

Having done SSM, the overall survival and the local recurrence rate has been reported to be similar to the cases underwent modified radical mastectomy $[1,12,14,25]$. In this retrospective study we didn't compare the rate of recurrence between skin sparing and standard mastectomy because we had selected the best-prognosis patients with very small tumor for skin-sparing mastectomy and this selection bias would affect any conclusion.

Although the follow up time in our series has not been long enough, there were few studies in which the follow up time of SSM reach as long as 6 years $[9,16,25,26]$. In the study reported by Spiegel et al. [26], the follow up time after SSM is at least six years and the incidence of local recurrence was 5.5\% for invasive carcinoma and $0 \%$ for in situ carcinoma. In the current study we had only one recurrence of tumor in the axilla of a patient with ductal carcinoma in situ 41 months after operation This low rate 
Table 3: local recurrence rate after Skin Sparing Mastectomy and immediate reconstruction in early breast cancer in previously published papers

\begin{tabular}{|c|c|c|c|}
\hline Author & Number of cases & Median follow-up (months) & Local recurrence (\%) \\
\hline Gerber [2] & 112 & 59 & 5.4 \\
\hline Carlson [13] & 327 & 42 & 4.8 \\
\hline Carlson [32] & 565 & 64.6 & 5.5 \\
\hline Carlson [34] & 223 & 82.3 & 4 \\
\hline Slavin [12] & 51 & 45 & 2.0 \\
\hline Kroll [15] & 104 & $>60$ & 6.7 \\
\hline Kroll [16] & 114 & 72 & 7 \\
\hline Fersis [I7] & 60 & 52 & 6.6 \\
\hline Rivadeneira [25] & 71 & 49 & 5.6 \\
\hline Medina-Franco [9] & 173 & 73 & 4.5 \\
\hline Spiegel [26] & 177 & 72 & 5.6 \\
\hline Newman [29] & 437 & 50 & 6.2 \\
\hline Toth [30] & 50 & 57 & 0 \\
\hline Singletary $[31]$ & 545 & $<60$ & 2.6 \\
\hline Peyser [23] & 71 & 24 & 3 \\
\hline Greenway [33] & 225 & 49 & 1.7 \\
\hline Current study & 95 & 59 & I.I \\
\hline
\end{tabular}

of local recurrence is similar to prior published series (table 3).

We propose that the low rate of local and systemic failure in our series could be as result of our studied population, which has been a special subset of very early breast cancer with inherently good outcome. Ubiruba et al. [27], reported three cases of local recurrence at the needle biopsy site in patients treated with SSM whose diagnoses were obtained through sterotactic needle biopsy. Thirtysix percent of our patients had history of core needle biopsy but fortunately without any local recurrence at the needle biopsy site.

Although the majority of our patients had in situ breast cancer and small invasive breast carcinoma with extensive in situ component, more recently SSM has been used to treat more advanced disease with local recurrence rates increasing with more advanced stages [28].

\section{Conclusion}

In conclusion SSM appears to be oncologically safe for early breast cancer (stage 0-II), but its use for more advanced stages require more prospective analysis.

\section{Competing interests}

The authors declare that they have no competing interests.

\section{Authors' contributions}

RO carried out data collection and drafted the manuscript. JYB carried out all the surgical procedure and followed the patients. ME carried out aesthetic evaluation and participated in drafting the manuscript. All authors read and approved the final manuscript.

\section{References}

I. Toth BA, Lappert P: Modified skin sparing incision for mastectomy: The need for plastic surgical input in preoperative planning. Plast Reconst Surg 1991, 87: I048-1053.

2. Gerber B, Krause A, Reimer T, Muller H, Kuchenmeister I, Makovitzky J, Kundt G, Friese K: Skin sparing mastectomy with conservation of the nipple-areole complex and autologous reconstruction is an oncologically safe procedure. Ann Surg 2003, 238: I20- I 27.

3. Laronga C, Kempt B, Johnston D, Robb GL, Singletary SE: The incidence of occult nipple-areole complex involvement in breast cancer patient receiving skin sparing mastectomy. Ann Surg Oncol 1999, 6:609-613.

4. Hudson DA, Dent DM, Lazarus D: One stage immediate breast reconstruction and nipple-areole reconstruction with autologus tissue. Ann Plast Surg 2000, 45:47I-476.

5. Afifi RY, El-Hindawy A: analysis of nipple-areolar complex involvement with mastectomy: can the nipple be preserved in Egyptian patients receiving skin-sparing mastectomy? Breast J 2004, 10:543-545.

6. Simmons RM, Brennan M, Christos P, King V, Osborne M: Analysis of nipple-areole involvement with mastectomy : can the areole be preserved? Ann Surg Oncol 2002, 9: I65-168.

7. Ho CM, Mak CK, Lau Y, Cheung WY, Chan MC, Hung WK: Skin involvement in invasive breast carcinoma: safety of skin sparing mastectomy. Ann Surg Oncol 2003, 10:102-107.

8. Carlson GW, Styblo TN, Lyles RH, Bostwick J, Murray DR, Staley CA, Wood WC: Local recurrence after skin sparing mastectomy: tumor biology or surgical conservatism? Ann Surg Oncol 2003, I0:108-I|2.

9. Medina-Franco H, Vasconez LO, Fix RJ, Heslin MJ, Beenken SW, Bland $\mathrm{KI}$, Urist MM: Factor associated with local recurrence after skin-sparing mastectomy and immediate breast reconstruction for invasive breast cancer. Ann Surg 2002, 235:8|4-8I9.

10. Simmons RM, Adamovich TL: Skin-sparing mastectomy. Surg Clin North Am 2003, 83:885-899.

II. Sotheran WJ, Rainsbury RM: Skin-sparing mastectomy in the UK - a review of current practice. Ann R Coll Surg Engl 2004, 86:82-86.

12. Slavin SA, Schnitt SJ, Duda RB, Houlihan MJ, Koufman CN, Morris DJ, Troyan SL, Goldwyn RM: Skin sparing mastectomy and immediate reconstruction: oncologic risk and aesthetic results in patients with early-stage breast cancer. Plast Reconstr Surg 1998, I02(I):49-62.

13. Carlson GW, bostwick J, Styblo TM, Moore B, Bried JT, Murray DR, Wood WC: Skin sparing mastectomy oncologic and reconstructive considerations. Ann Surg 1997, 225:570-578. 
14. Simmons RM, Kersey Fish S, Gayle L, La Trenta GS, Swistel A, Christos P, Osborne MP: Local and distant recurrence rates in skin sparing mastectomies compared with non- skin- sparing mastectomies. Ann Surg Oncol 1999, 6:676-68I.

15. Kroll SS, Schusterman MA, Tadjalli HE, Singletary SE, Ames FC: Risk of recurrence after treatment of early breast cancer with skin-sparing mastectomy. Ann Surg oncol 1997, 4:193-197.

16. Kroll SS, Khoo A, Singletary SE, Ames FC, Wang BG, Reece GP, Miller $M J$, Evans GR, Robb GL: Local recurrence risk after skin sparing and conventional mastectomy:a 6-yr follow-up. Plast Reconstr Surg 1999, 104:42I-425.

17. Fersis N, Hoenig A, Relakis K, Pinis S, Wallwiener D: Skin sparing mastectomy and immediate breast reconstruction: incidence of recurrence in patients with invasive breast cancer. Breast 2004, I 3:488-493.

18. Greene FL, Page DL, Fleming ID, Fritz A, Balch CM, Haller DG, Morrow M, Eds: AJCC Cancer Staging Manual. 6th edition. New York: Springer; 2002.

19. Lowery JC, Wilkins EG, Kuzon WM, Davis JA: Evaluation of aesthetic results in breast reconstruction: an analysis of reliability. Ann Plast Surg 1996, 36:60 I-606.

20. Torresan RZ, dos Santos CC, Okamura H, Alvarenga M: Evaluation of residual glandular tissue after skin-sparing mastectomies. Ann Surg Oncol 2005, 12:1037-1044.

21. Carlson GW, Grossl N, Lewis MM, Temple JR, Styblo TM: Preservation of the inframammary fold: what are we leaving behind? Plast Reconstr Surg 1996, 98:447-450.

22. Rainsbury RM: Skin-Sparing Mastectomy. Br J Surg 2006, 93:276-28I.

23. Peyser PM, Abel JA, Straker VF, Hall VL, Rainsbury RM: Ultra-conservative skin-sparing "keyhole" mastectomy and immediate breast and areola reconstruction. Ann R Coll Surg Engl 2000 , 82:227-235.

24. Allweis TM, Boisvert ME, Otero SE, Perry DJ, Dubin NH, Priebat DA: Immediate reconstruction after mastectomy for breast cancer does not prolong the time to starting adjuvant chemotherapy. Am / Surg 2002, 183:218-22I.

25. Rivadeneira DE, Simmons RM, Fish SK, Gayle L, La Trenta GS, Swistel A, Osborne MP: Skin-sparing mastectomy with immediate breast reconstruction: a critical analysis of local recurrence. Cancer 2000, 6(5):331-335.

26. Spiegel A, Butler C: Recurrence following treatment of ductal carcinoma in situ with skin sparing mastectomy and immediate breast reconstruction. Plast Reconstr Surg 2003, I I I:706-7| I.

27. Ubirubu JL, Vuoto HD, Cogorno L, Isetta JA, Candas G, Imach GC, Bernabo OL: Local recurrence of breast cancer after skinsparing mastectomy following core needle biopsy: case reports and review of the literature. Breast J 2006, I 2: 194- 198.

28. Foster RD, Esserman LJ, Anthony JP, Hwang ES, Do H: Skin sparing mastectomy and immediate breast reconstruction: a prospective cohort study for the treatment of advanced stages of breast carcinoma. Ann Surg Oncol 2002, 9:462-466.

29. Newman LA, Kuerer HM, Hunt KK, Kroll SS, Ames FC, Ross MI, Feig BW, Singletary SE: Preservation, treatment and outcome of local recurrence after skin sparing mastectomy and immediate breast reconstruction. Ann Surg Oncol 1998, 5:620-626.

30. Toth BA, Forley BG, Calabria R: Retrospective study of the skinsparing mastectomy in breast reconstruction. Plast Reconstr Surg 1999, 104:77-84.

31. Singletary SE, Kroll SS: Skin sparing mastectomy with immediate breast reconstruction. Adv Surg 1996, 30:39-52.

32. Carlson GW, Styblo TM, Lyles RH, Jones G, Murray DR, Staley CA, Wood WC: The use of skin sparing mastectomy in the treatment of breast cancer: The Emory experience. Surg Oncol 2003, I 2:265-269.

33. Greenway RM, Schlossberg L, Dooley WC: Fifteen-year series of skin-sparing mastectomy for stage 0 to 2 breast cancer. $\mathrm{Am}$ J Surg 2005, 190:918-922.

34. Carlson GW, Page A, Johnson E, Nicholson K, Styblo TM, Wood WC: Local recurrence of ductal carcinoma in situ after skinsparing mastectomy. J Am Coll Surg 2007, 204:1074- 1078.
Publish with Bio Med Central and every scientist can read your work free of charge

"BioMed Central will be the most significant development for disseminating the results of biomedical research in our lifetime. "

Sir Paul Nurse, Cancer Research UK

Your research papers will be:

- available free of charge to the entire biomedical community

- peer reviewed and published immediately upon acceptance

- cited in PubMed and archived on PubMed Central

- yours - you keep the copyright

Submit your manuscript here:

http://www.biomedcentral.com/info/publishing_adv.asp
BioMedcentral 